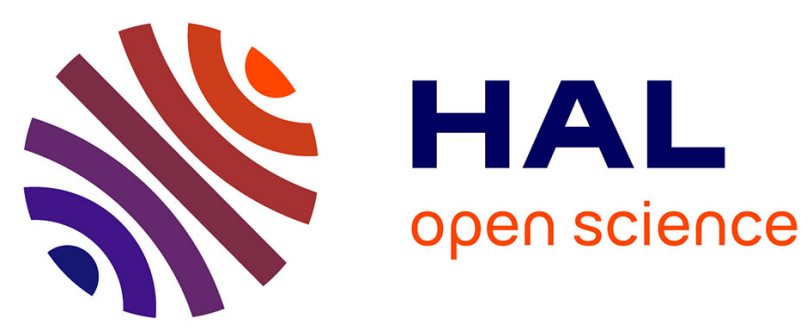

\title{
Electrical characteristics of a vertically integrated field-effect transistor using non-intentionally doped $\mathrm{Si}$ nanowires \\ G. Rosaz, B. Salem, N. Pauc, P. Gentile, A. Potié, T. Baron
}

\section{- To cite this version:}

G. Rosaz, B. Salem, N. Pauc, P. Gentile, A. Potié, et al.. Electrical characteristics of a vertically integrated field-effect transistor using non-intentionally doped Si nanowires. Microelectronic Engineering, 2011, pp.(July 2011) doi:10.1016/j.mee.2011.07.009. hal-00629234

\section{HAL Id: hal-00629234 \\ https://hal.science/hal-00629234}

Submitted on 24 Jan 2019

HAL is a multi-disciplinary open access archive for the deposit and dissemination of scientific research documents, whether they are published or not. The documents may come from teaching and research institutions in France or abroad, or from public or private research centers.
L'archive ouverte pluridisciplinaire HAL, est destinée au dépôt et à la diffusion de documents scientifiques de niveau recherche, publiés ou non, émanant des établissements d'enseignement et de recherche français ou étrangers, des laboratoires publics ou privés. 
Electrical characteristics of a vertically integrated field-effect transistor using non-intentionally doped Si nanowires

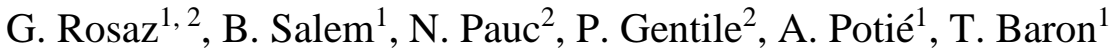

${ }^{1}$ Laboratoire des Technologies de la Microélectronique (LTM) -UMR 5129 CNRS, CEA Grenoble, 17 Rue des Martyrs, F-38054 Grenoble, France

${ }^{2}$ CEA Grenoble, INAC/SP2M/SiNaPS, 17 Rue des Martyrs, F-38054 Grenoble, France

\title{
$\underline{\text { Abstract }}$
}

In this letter, we report the fabrication and the electrical characterization of Vertical Gate All Around Field-Effect Transistors (GAA-FET) using non intentionally doped Silicon NanoWires (SiNWs) grown by Chemical Vapor Deposition (CVD) using the Vapor-LiquidSolid (VLS) mechanism as conduction channel. The SiNWs GAA-FET devices exhibited nchannel type semiconductor behavior with a threshold voltage at room temperature around $1.15 \mathrm{~V}$, a high $\mathrm{I}_{\mathrm{ON}} / \mathrm{I}_{\mathrm{OFF}}$ ratio up to $10^{6}$ with a low Ioff current about $1 \mathrm{pA}$, a maximum transconductance $\left(\mathrm{g}_{\mathrm{m}, \max } \sim 0.9 \mu \mathrm{S}\right.$ at $\mathrm{V}_{\mathrm{GS}}=-0.65 \mathrm{~V}$ and $\left.\mathrm{V}_{\mathrm{DS}}=1 \mathrm{~V}\right)$ and a minimum inverse subthreshold slope around $145 \mathrm{mV} /$ decade. In light of these characteristics, these devices can be suitable for high performance, low power consumption components and especially for high density integration in integrated circuits (ICs) interconnections regarding to their 3D architecture.

$\underline{\text { Introduction }}$ 
Bottom-up approach has opened a new route for building blocks of future device applications such as field effect transistors, laser diodes, photovoltaic devices ${ }^{[1-2]}$. The properties of nanowires have been widely studied mainly in planar configuration ${ }^{3,4}$ but recently it has been demonstrated that it is possible to use them as the conduction channel of vertical FET with the bulk-nanowire epitaxial interface as a source or drain contact. Different materials have been investigated such as $\mathrm{ZnO}^{5}$, InAs ${ }^{6,7,8,9}$, and $\mathrm{Si}^{10,11,12,13}$. One benefit of vertical integration is the possibility to build a wrapping gate with a cylindrical geometry which enhances the electrostatic gate coupling and improves the control of the gate potential in the wire body compared with planar devices. This configuration allows to build high performance and low power FET combined with a 3D integration providing a very promising way to increase the integration density on microelectronic circuits. Indeed the vertical integration offers a new option to integrate much more devices than in planar approach for the same surface area which is one of the mainstreams of microelectronics technology ${ }^{14}$.

In this letter we report the fabrication and the electrical performance of a non-intentionally doped vertical SiNWs GAA FET using a generic process, which is also described. This process requires non critical lithographic steps and allows the interconnection of many nanowires at the same time. Electrical performances are discussed and technological improvements are proposed in order to obtain better devices characteristics.

\section{Experimental}

The starting material for NW growth was $<111>$-oriented n-type Si wafers $(1 \mathrm{~m} \Omega . \mathrm{cm})$. In order to open windows for the localized deposition of NW catalyst, substrates were patterned using photolithography, resist wastes were cleaned with oxygen plasma at $450 \mathrm{~W}$ for $60 \mathrm{~s}$ and native oxide was removed by dipping into HF (10\%) for $10 \mathrm{~s}$. Gold colloids acting as catalysts for the VLS growth were then deposited onto the patterned substrates by drop casting a droplet of colloidal solution mixed with another droplet of HF (10\%) to increase the colloid 
precipitation onto the surface. After $30 \mathrm{~s}$ the substrate was rinsed with deionised water and dried under nitrogen. Finally lift-off was used to remove the resist from the substrates and leave localized gold colloids (Fig. 1. (a)). SiNWs growth was performed in a CVD furnace at $600^{\circ} \mathrm{C}$ using a 30 mTorr silane partial-pressure with $\mathrm{H}_{2}$ as carrier gas and $100 \mathrm{sccm} \mathrm{HCl}$ to inhibit the gold diffusion and 2D growth ${ }^{15}$. The as-grown vertically standing $<111>$-oriented NWs are typically $2.5 \mu \mathrm{m}$ in length and $100 \mathrm{~nm}$ in diameter. Immediately after growth, gold catalyst was removed from the top of the wires using KI: $\mathrm{I}_{2}$ solution followed by a thermal oxidation in a Rapid Thermal Process (RTP) furnace at $800{ }^{\circ} \mathrm{C}$ under $2000 \mathrm{sccm}$ of oxygen to create an uniform $\mathrm{SiO}_{2}$ layer leading to a $\mathrm{SiO}_{2}$ shell dielectric layer around $10 \mathrm{~nm}$.

As gate electrode a $70 \mathrm{~nm}$ thick $\mathrm{Al}$ film was deposited by sputtering. A photoresist was spincoated and a photolithography step was used to define gate pads. The photoresist was then etched-back to define the gate length. Using the resist as a mask, the $\mathrm{Al}$ was then etched from the top of the wire by wet etching as shown on Fig. 1(b). The wafer was coated with a polymer layer (Fig. 1 (d)), which was again etched-back to reveal the top of the wires. The drain contact was defined by photolithography, then thermal oxide was removed and the drain was metalized with Ti/Au. Gate contact was reached by a last oxygen plasma etch step using drain contact as a mask (Fig. $1(\mathrm{c})$ ). Finally, the gate length $\left(\mathrm{L}_{\mathrm{G}}\right)$ of all the devices was around $1.5 \mu \mathrm{m}$.

\section{$\underline{\text { Discussion }}$}

Typical output characteristic of a SiNWs GAA FET device is displayed in Fig. 2 (b). The mean diameter of the oxidized wires is about $115 \mathrm{~nm}$. The FET has $\mathrm{n}$-type behavior as verified from the conductance increase when we increase the gate voltage bias (Fig.2 (a)). We show that the subthreshold slope, which is a key parameter for low power switching applications, is around $145 \mathrm{mV} /$ decade but is still more than twice the theoretical room temperature limit of $60 \mathrm{mV} / \mathrm{decade}$. In fact, the thermal oxide being quite thin the explanation 
of this high value can be given by a poor $\mathrm{Si} / \mathrm{SiO}_{2}$ interface and would be improved by a thermal annealing under forming gas. The $\mathrm{I}_{\mathrm{ON}} / \mathrm{I}_{\mathrm{OFF}}$ ratio which is the ratio of $\mathrm{I}_{\mathrm{DS}}$ at current saturation (ION) to IDs at depletion (IOFF) is close to $10^{6}$ (Fig. 2 (a)). We would mention that this $\mathrm{I}_{\mathrm{ON}} / \mathrm{I}_{\mathrm{OFF}}$ ratio is the highest obtained for vertical GAA FET using un-doped silicon nanowires as a channel elaborated by CVD. Moreover the hysteresis effect during gate voltage sweep being very small gives to the device reproducible electrical characteristics. This hysteresis value does not vary with gate voltage sweep rate contrary to planar devices ${ }^{16,17}$ which is also relevant of the efficient passivation of the wires and most of all of their embedding in polymer. Despite of this good passivation this polymer could be the source of a highest hysteresis than air if the surface of the wire was not oxidized. Finally as shown on Fig.2 (a) the threshold voltage which is around $-1.15 \mathrm{~V}$, close to the silicon gap, with a maximum deviation of $15 \%$ does not change either with gate voltage sweep direction or rate as previously shown by ${ }^{13}$. Contrary to what has been observed in III/V nanowires ${ }^{12}$ the threshold voltage does not vary with $\mathrm{V}_{\mathrm{DS}}$ which is more suitable for reproducible behavior of the devices.

The transconductance defined as $\mathrm{g}_{\mathrm{m}}=\mathrm{dI} \mathrm{ISS}_{\mathrm{DS}} / \mathrm{dV}_{\mathrm{GS}}$ is calculated to be close to $0.9 \mu \mathrm{S}$ as shown in Fig. 3. The electron mobility is $\mu=g_{m} L_{G}^{2} /\left(C_{o x} N V_{D S}\right)$, where $L_{G}$ is the gate length, $N$ is the number of nanowires, and $\mathrm{C}_{\mathrm{ox}}$ is the gate capacitance for a single nanowire. The gate capacitance is expressed as $\mathrm{C}_{\mathrm{ox}}=2 \pi \varepsilon_{0} \varepsilon_{\mathrm{ox}} \mathrm{L} / \mathrm{ln}\left(\mathrm{r}_{\mathrm{g}} / \mathrm{r}_{\mathrm{nw}}\right)$, where $\varepsilon_{0}$ is the vacuum permittivity, $\varepsilon_{\mathrm{ox}}$ is the dielectric constant of the gate oxide, $r_{g}$ is the inner radius of the gate electrode, and $r_{n w}$ is the nanowire radius. This calculus gives us an electron field-effect mobility from 1 to 11 $\mathrm{cm}^{2} / \mathrm{V}$.s with an average value of $7 \mathrm{~cm}^{2} / \mathrm{V}$.s depending on the number of connected nanowires which is far from the bulk value $\left(\sim 1350 \mathrm{~cm}^{2} / \mathrm{V} . \mathrm{s}\right)$. The main reason explaining the small value of $\mu_{\mathrm{e}}$ is probably the high access resistance at the un-gated top part of the nanowires just below the drain contact which is about one third of the total channel length and this effect has 
already been pointed out by Björk et $a l^{12}$ and recently simulated by Karmalkar et $\mathrm{al}^{18}$. Such a resistive part in our devices could also explain the low current level observed in the ON state. This problem can be solved either using doped nanowires on their top part or using a silicided contact in order to control the length of the un-gated region of the wires. This point is under study.

In summary we have shown that it is possible to build vertical SiNWs based GAA-FET with good electrical characteristics such as a low subthreshold slope of $145 \mathrm{mV} /$ decade, a high ION/IOFF ratio up to $10^{6}$ which is the highest value reported for VLS grown undoped silicon nanowires vertical FET. Despite the fact this ratio is remarkably good it is still possible to improve it by playing on the contacts quality in order to obtain better carriers injection in the channel. Our devices exhibited low hysteresis effect demonstrating a good surface passivation of the nanowires. We confirm that improvements should be performed to obtain a better carriers mobility using either doped or silicided contacts in order to reduce the access resistance of the drain and also using forming gas annealing step to improve the $\mathrm{Si} / \mathrm{SiO}_{2}$ interface. 
Figure captions

Figure 1: Vertical SiNW transistor process flow illustration. (a) Si nanowire localized in a square of $20 \times 20 \mu \mathrm{m}^{2}$. (b) $115 \mathrm{~nm}$ diameter oxidized Si nanowire with a $10 \mathrm{~nm}$ thermal $\mathrm{SiO}_{2}$ shell and a $70 \mathrm{~nm} \mathrm{Al}$ thick gate of $1.5 \mu \mathrm{m}$ length. (c) Top view of a final device with gate and drain contacts after gate opening in oxygen plasma. d) Schematics of the gate-all-around transistor exhibiting a large un-wrapped region of $700 \mathrm{~nm}$ under the top contact.

Figure 2: (a) Drain-source current $\mathrm{I}_{\mathrm{DS}}$ versus gate voltage $\mathrm{V}_{\mathrm{GS}}$ at $\mathrm{V}_{\mathrm{DS}}=1 \mathrm{~V}$. The device exhibits an ION-IOFF current ratio of $10^{6}$ and a threshold voltage of $-1.15 \mathrm{~V}$ as shown in inset. (b) Output characteristic of an array of ten nanowires for different gate voltages. Both graphics clearly show that the channel of the device has n-type semiconductor behavior.

Figure 3 : Transconductance of the device plotted versus the gate voltage for a $\mathrm{V}_{\mathrm{DS}}=1 \mathrm{~V}$. The maximum value $\mathrm{g}_{\mathrm{m}, \max }=0.9 \mu \mathrm{S}$ is reported for $\mathrm{V}_{\mathrm{GS}}=-0.65 \mathrm{~V}$ 


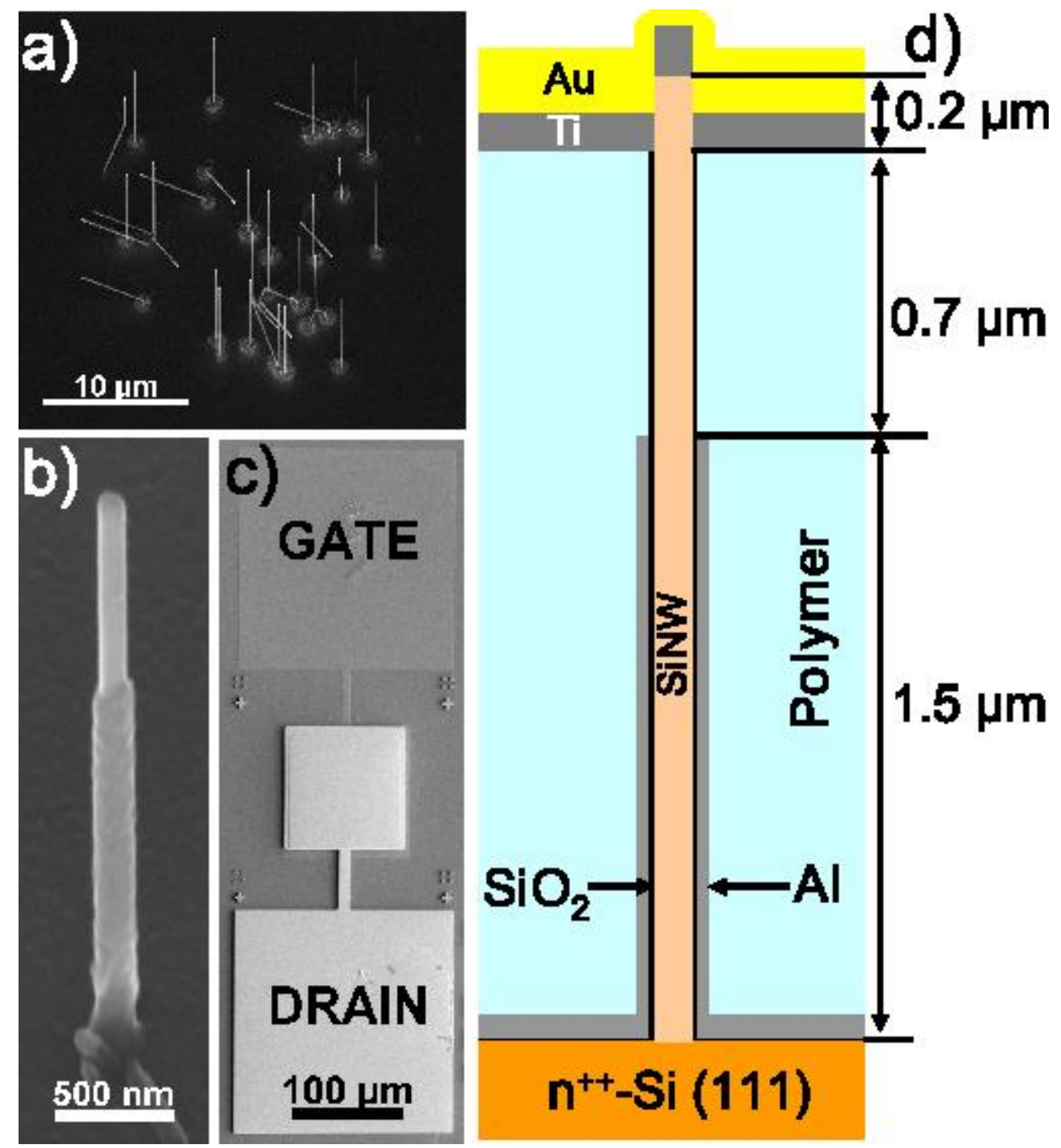

Figure 1 

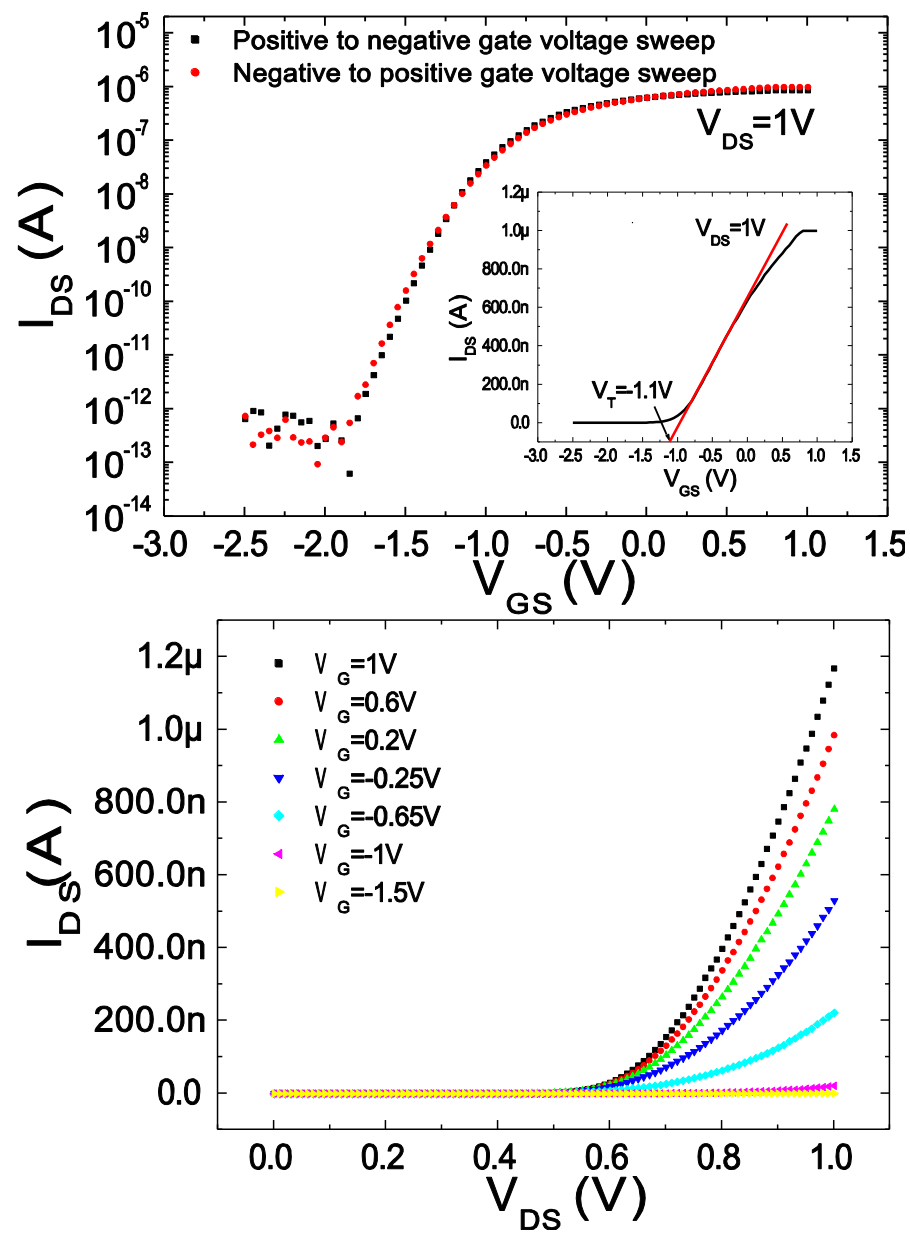

Figure 2 


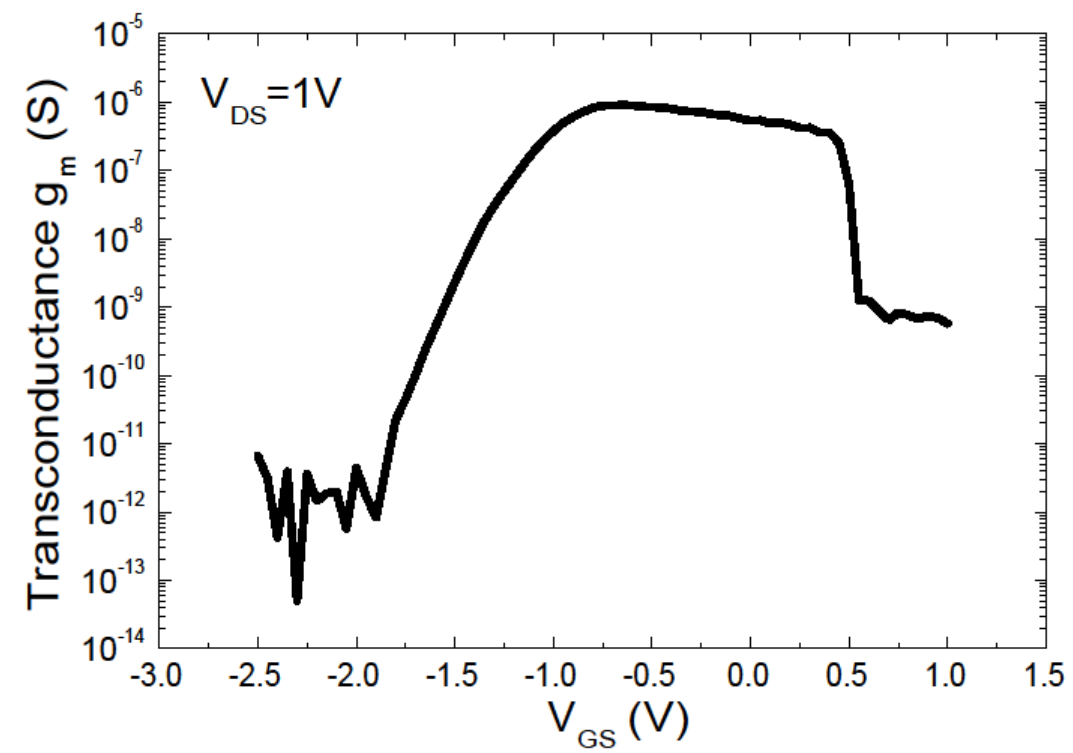

Figure 3 
References :

${ }^{1}$ Andrew B. Greytak, Carl J. Barrelet, Yat Li, and Charles M. Lieber, Appl. Phys. Lett. 87, 151103 (2005).

${ }^{2}$ J. Xiang, W. Lu1, Y. Hu, Y. Wu, H. Yan and C. M. Lieber, Nature 441 (2006), 489

${ }^{3}$ B. Salem, F. Dhalluin, H. Abed, T. Baron, P. Gentile, N. Pauc, P. Ferret, Solid State Commun. 149 (2009), 799.

${ }^{4}$ O. Hayden, M. T. Bjçrk, H. Schmid, H. Riel, U. Drechsler, S. F. Karg, E. Lçrtscher, and W. Riess, Small 3 (2) 2007, 230.

${ }^{5}$ H. T. Ng, J. Han, T. Yamada, P. Nguyen, Y. P. Chen, and M. Meyyappan, Nano Lett. 4 (2004), 1247.

${ }^{6}$ T. Bryllert, L.-E. Wernersson, T. Löwgren and L. Samuelson, Nanotechnology 17 (2006), S227

${ }^{7}$ L.-E. Wernersson, E. Lind, L. Samuelson, T. Löwgren, J. Ohlsson, Jpn. J. Appl. Phys. 46 (2007), 2629

${ }^{8}$ M. Egard, S. Johansson, A.-C. Johnasson, K.-M. Persson, A. W. Dey, B. M. Borg, C. Thelander, L.-E. Wernersson, and E. Lind, Nano Lett 10 (2010), 809

${ }^{9}$ T. Tanaka, K. Tomioka, S. Hara, J. Motohisa, E. Sano, and T. Fukui, Appl. Phys. Express 3 (2010) 025003

${ }^{10}$ V. Schmidt, H. Riel, S. Senz, S. Karg, W. Riess, and U. Gösele, Small 2 (2006), 85

${ }^{11}$ J. Goldberger, A. I. Hochbaum, R. Fan, and P. Yang. Nano Lett. 6 (2006), 973

${ }^{12}$ M. T. Björk, O. Hayden, H. Schmid, H. Riel, and W. Riess, Appl. Phys. Lett. 90 (2007), 142110

${ }^{13}$ A. Lugstein, M. Steinmair, C. Henkel, and E. Bertagnolli, Nano Lett. 9 (2009), 1830

${ }^{14}$ International Technology Roadmap for Semiconductors 2010. http://www.itrs.net.

${ }^{15}$ F. Oehler, P. Gentile, T. Baron and P. Ferret, Nanotechnology 20 (2009), 475307

${ }^{16}$ Z. Fahem, G. Csaba, C. M. Erlen, P. Lugli, W. M. Weber, L. Geelhaar, and H. Riechert Phys. Stat. Sol. 5 (2008), 27

${ }^{17}$ S. A. Dayeh, C. Soci, P. K. L. Yu, E. T. Yu, and D. Wang J. Vac. Sci. Technol. 25 (2007), 1432

${ }^{18}$ S. Karmalkar, K. R. K. Maheswaran, and V. Gurugubelli, Appl. Phys. Lett. 98 (2011), 063508 